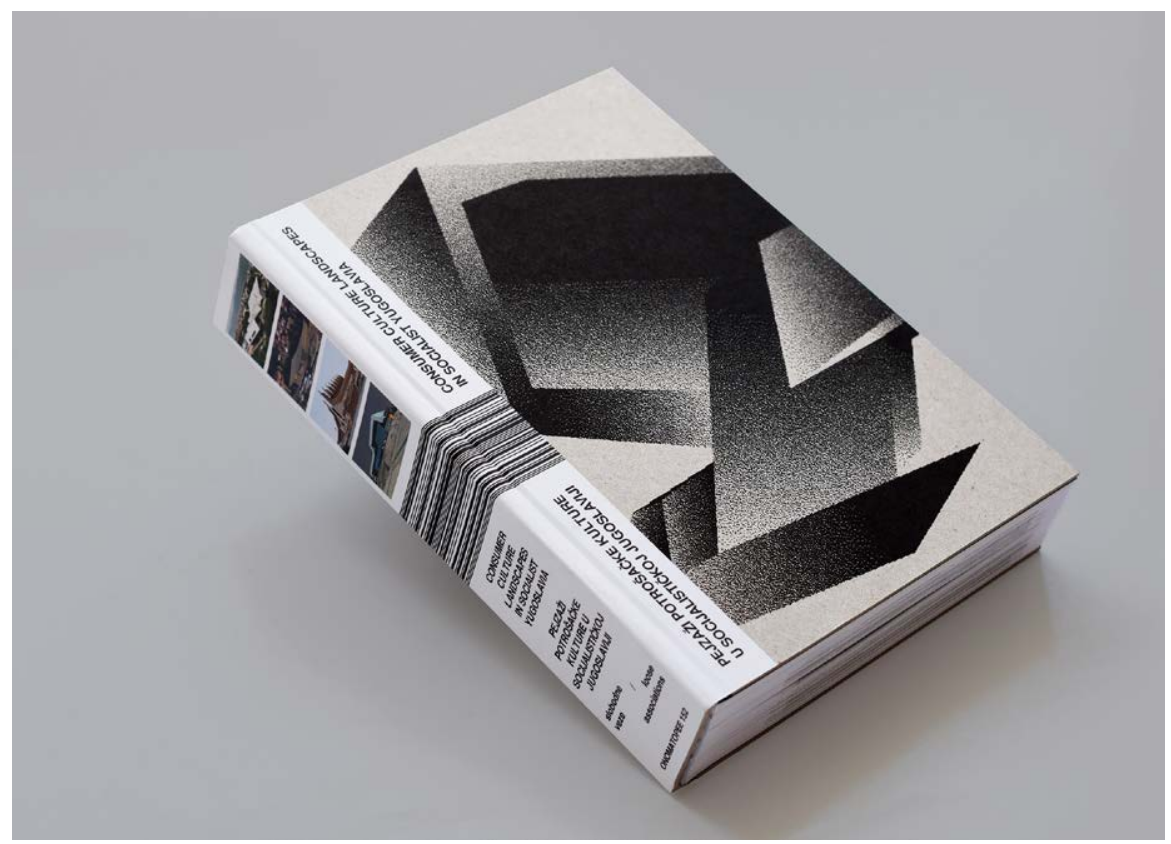

Pejzaži potrošacke kulture u socijalističkoj Jugoslaviji, ur. Nataša Bodrožić, Lidija Butković Mićin, Saša Šimpraga. Zagreb: Slobodne veze, udruga za suvremene umjetničke prakse / Eindhoven: Onomatopee, 2018. 


\section{Svjetonazor i povijest}

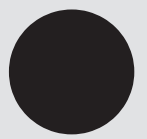

Pejzaži potrošačke kulture u socijalističkoj Jugoslaviji, ur. Nataša Bodrožić, Lidija Butković Mićin, Saša Šimpraga. Zagreb: Slobodne veze, udruga za suvremene umjetničke prakse/Eindhoven: Onomatopee, 2018. ISBN 9789537703400

DOI: 10.31664/zu.2019.105.11

„Svaka fotografija obuhvaća unutar svojih granica samo dio svijeta. Niz fotografija međutim, snimljenih kroz više godina i pažljivo uređenih, otkrivaju svjetonazor." Ovim jednostavnim, ali sugestivnim riječima Teju Cole uvodi nas u rad velikoga indijskog fotografa Raghubira Singha, sintetizirajući odnos između njegovih pojedinih fotografskih snimaka i cjelokupnog opusa. Singh, kako je poznato, posvetio je cijelu svoju karijeru isključivo jednoj temi, a to je manijakalno ulično dokumentiranje ljudi, čime je možda na najbolji mogući način oslikao i opisao svoju domovinu i njezine transformacije od pedesetih godina naovamo. Posuđujemo konceptualizaciju Singhova rada, koju nam nudi ovaj američko-nigerijski fotograf i esejist, kao neku vrstu hinta, sugestije za čitanje knjige Pejzaži potrošačke kulture u socijalističkoj Jugoslaviji / Consumer Culture Landscapes in Socialist Yugoslavia, a koju su spretno uredili Nataša Bodrožić, Lidija Butković Mićin i Saša Šimpraga.

Ova bogata dvojezična publikacija u metodološkom je smislu ambiciozan i uspio primjer multidisciplinarne analize: jedan subjekt-sportski i trgovački centar Koteks u Splitu arhitekata Živorada Jankovića i Slavena Rožića-ponuđen je na interpretaciju autorima iz raznih struka i disciplina. Povjesničari, novinari, arhitekti, sociolozi, kustosi, povjesničari arhitekture i povjesničari umjetnosti u okviru su svojih interesnih sfera doprinijeli boljem poznavanju ovog objekta i njegovoj adekvatnoj kontekstualizaciji; s druge strane, umjetnici i aktivisti upotrijebili su ovu arhitekturu za svoje performanse i provokacije, pridavši joj tako i neka alternativna značenja te tumačenja.

$\rightarrow$

\section{Luka Skansi}

Odsjek za arhitekturu i urbane studije, Politehničko Sveučilište u Milanu 


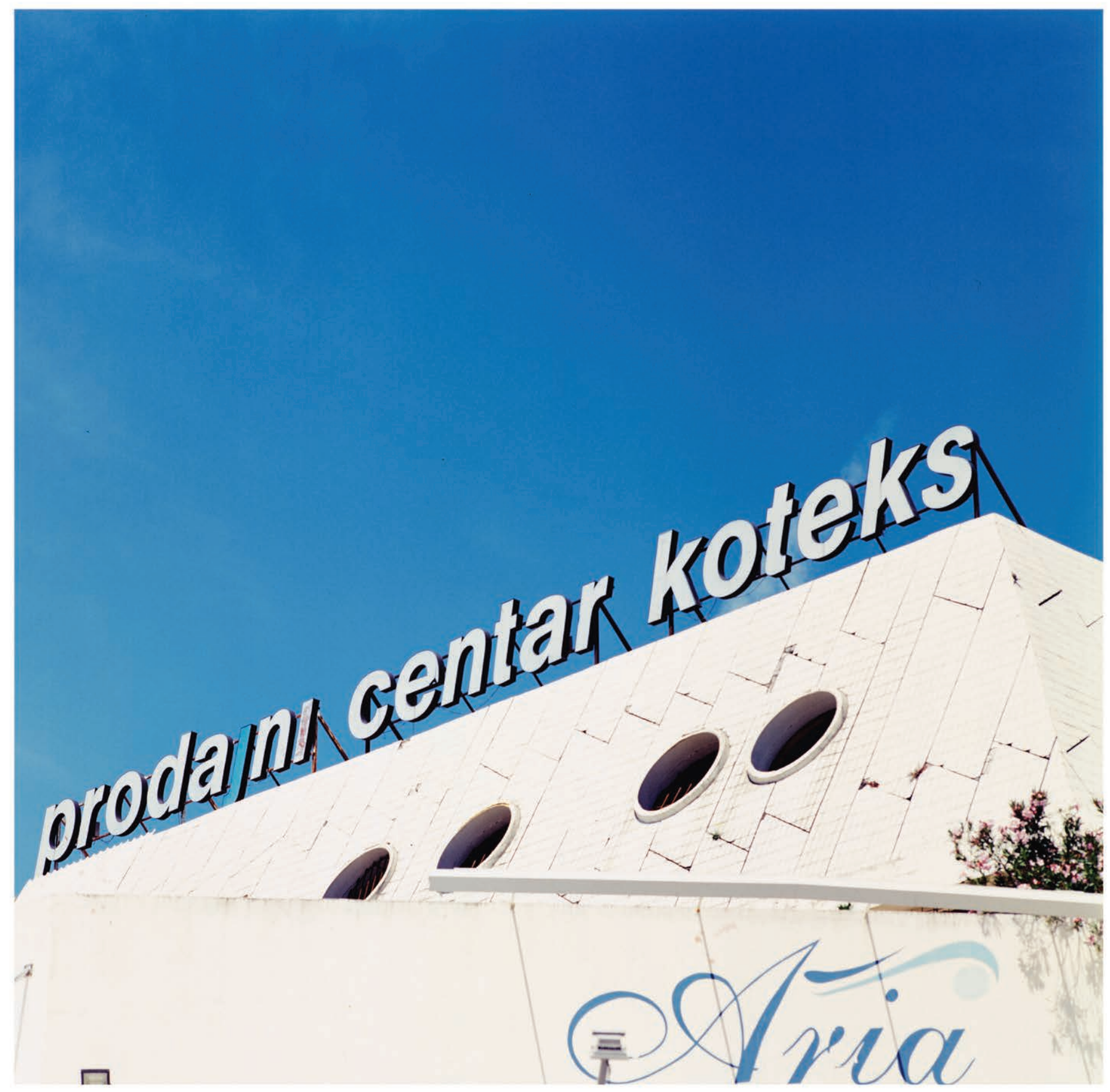


Ako se kratko vratimo na Tejua Colea, knjiga koju predstavljamo u stvari je kolekcija „fotografija” ili tekstualnih analiza i dokumenata, koji nam prenose „dijelove svijeta” koji su-ma koliko sami po sebi značajni i puni sadržaja-ipak samo fragmenti jedne šire priče. Čin sakupljanja i uređivanja tih ulomaka sam je po sebi projekt kojim Bodrožić, Butković i Šimpraga oslikavaju jedan detaljniji i potpuniji pejzaž-pejzaž „potrošačke kulture socijalističke Jugoslavije”. Citirani je naslov obzirom na sadržaj knjige zapravo reduktivan. Kako se vrlo brzo može uočiti listajući i čitajući ovu knjigu, pejzaž koji autori ocrtavaju mnogo je širi i obuhvatniji od onoga što sam naslov označava: njihov je cilj istaknuti povijesne, sociološke, arhitektonske i prostorne vrijednosti ovoga ,impresivnog (post)modernističkog zdanja”, i to u trenutku njegove najveće ugroženosti i neizvjesnosti, u danima frenetične svakodnevice hiper-turističkog cvita mediterana i agresivne budućnosti koja se nazire. I tu nailazimo na svjetonazor: ova knjiga rezultat je uredničkog pothvata koji na svjesni, pomalo očajnički način signalizira nešto drugo, a to je smrt arhitekture i urbanizma (barem onog tipa kakav je postojao do osamdesetih godina) i devastacija arhitektonske baštine modernizma u suvremenoj Hrvatskoj. Priča o Koteksu nije u biti ništa drugo nego jedna tipična priča hrvatske (odnosno srpske, crnogorske, bosansko-hercegovačke, makedonske, kosovske) tranzicije iz socijalističke Jugoslavije, i njezina neuravnotežena prijelaza na tržišnu ekonomiju, prijelaza koji je na mjerilu urbanizma i posljedično arhitekture izazvao devastacije u svim većim gradovima Jugoslavije. Ovo je i priča-ma koliko god autori u knjizi to ne ističu-o totalnoj nemoći struke s jedne strane, i nadležnih institucija s druge, da očuvaju ili nanovo osmisle one vrijedne objekte koji karakteriziraju poslijeratnu urbanu, arhitektonsku i prostornu modernizaciju naših gradova. Objekte kao što je Koteks moguće je i potrebno upravo nanovo osmisliti, poštujući njihove arhitektonske i prostorne kvalitete. Objekti kao Koteks izrazito su značajni u gradotvornom smislu za današnji disperzni grad. No, za njegovo čuvanje i osmišljavanje treba imati kompetentne službe i prave investitore: ono što ne možemo zahtijevati od konzervatorskog zavoda kao što je splitski, koji do današnjeg dana nije bio sposoban ni prepoznati niti zaštiti svoj urbanistički dragulj dvadesetog stoljeća, Split 3, kao niti od suvremene kerumizacijske poduzetničke „kulture”, koja vlada na lokalnoj privrednoj sceni, kao niti od političkih "elita”, koje urbanizam shvaćaju na sasvim drugačiji način od onih koji su izgradili Koteks, Gripe, Poljud i Split 3.

Ova publikacija uključuje se tako u širi kontekst recentnog historiziranja poslijeratne arhitekture koji se odvija u svim post-jugoslavenskim državama, ali i u međunarodnome istraživačkom kontekstu čiji je doprinos, pogotovo poslije prošlogodišnje izložbe Toward a Concrete Utopia: Architecture in Yugoslavia 1948-1980 u MoMa-i, sve veći i raznovrsniji. Knjiga nemalo doprinosi, baš na metodološkom nivou, profiliranju tipologije pristupā u analizi arhitekture, odnosno arhitektonskih i urbanističkih cjelina u nas. Metodologija u ovoj publikaciji oblikuje se, dakle, pod utjecajem međunarodnih, pogotovo anglosaksonskih tendencija multidisciplinarne analize: nije dovoljno govoriti „samo” o arhitekturi, o njezinim povijesnim, formalnim i prostornim kvalitetama, već se interpretacija treba oslanjati na širi dijapazon vrijednosti, ponekad čak izlazeći iz okvira početnog predmeta analize i uopće iz sfere povijesti arhitekture, odnosno dajući prednost nekim aktualnijim, često ideološki jasno aspektiranim iščitavanjima. $U$ tom smislu treba upozoriti i na manje nedostatke ove publikacije; u njoj se, naime, nedovoljno valorizira povijesna i politička ulogu sporta u izgradnji Jugoslavije i njezinih gradova (u tom kontekstu, prvo mjesto po važnosti u povijesti Splita ipak pripada sportskom centru Gripe, a tek onda trgovačkom centru Koteks); također, bilo bi zanimljivo u njoj pročitati analizu i historizaciju konstrukcijskog istraživanja Živorada Jankovića na temi velikih raspona, koje predstavlja jednu od važnih i zaključnih poglavlja u povijesti odnosa arhitekture i inženjerstva, a koji je u Jugoslaviji dao fantastične rezultate i rezultirao bogatom tradicijom (konstrukcija je, primjerice, glavni čimbenik oblikovnog jezika pete fasade Gripa, vidljive iz cijelog grada prema jugu). 


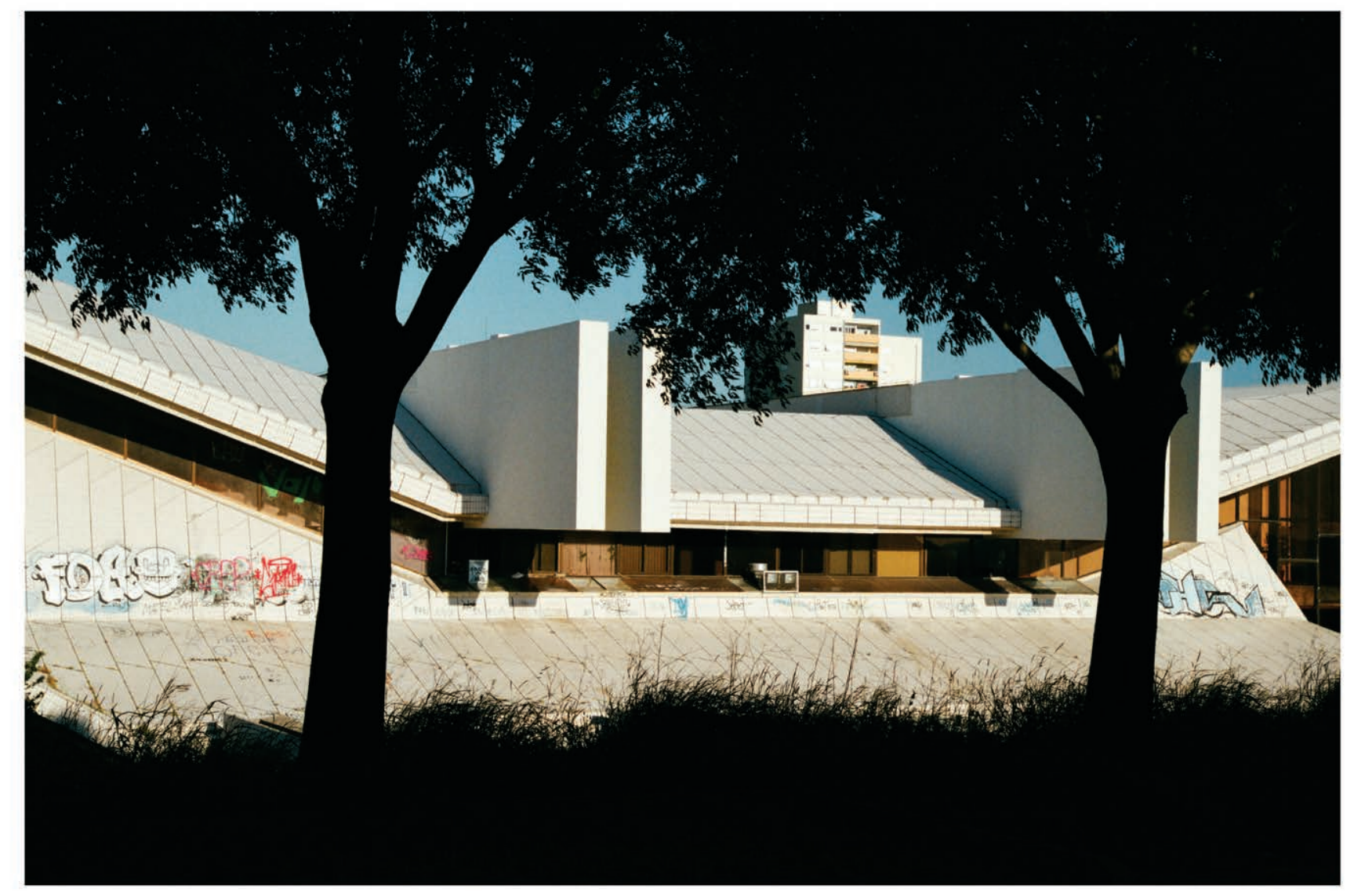




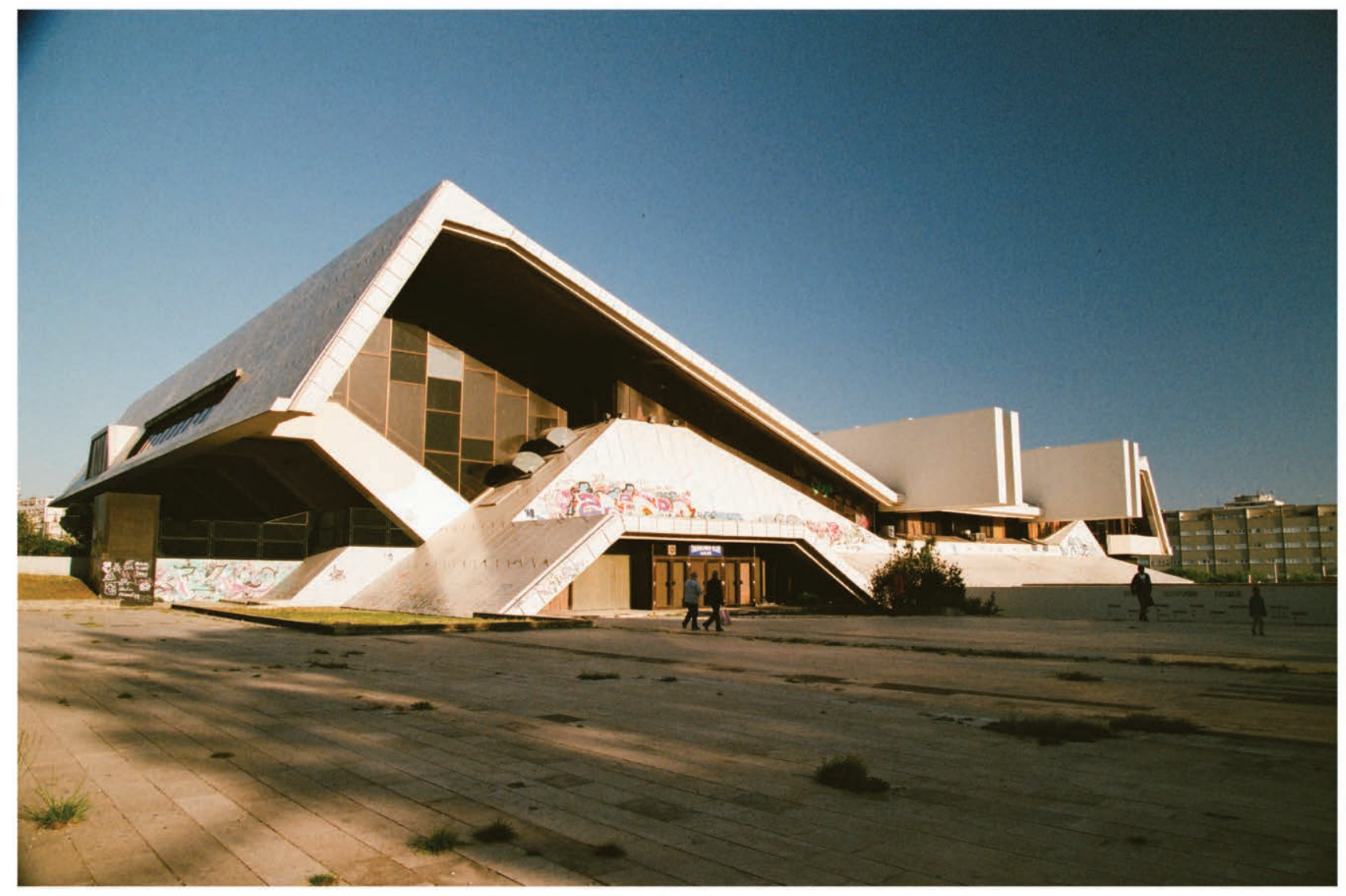


No, značaj je ove publikacije, ponavljamo, upravo u svjetonazoru koji zastupa i u velikoj dozi civilnog aktivizma njezinih urednika-autori, naime, nisu novi u ovakvim „operacijama”; podsjećamo na vrijednu inicijativu Motel Trogir, koja je svakako bila uzorom i projektu Koteks. Ovaj aktivistički svjetonazor koji, naoružan multidisciplinarnošću, ukazuje na položaj arhitekture u današnjoj Hrvatskoj nadilazi suhoparne opaske kritičara iz akademske zajednice kao što je naša. I dokazuje kako intervencija povijesničara i arhitekata ne samo da smije već i treba imati ideološke te etičke premise. Jer bitke koje se danas vode su mnogo veće od onih koje se odvijaju unutar svijeta učionica i znanstvenoistraživačkih konferencija. Od naše se discipline danas zahtijeva borba protiv onoga političkog narativa koji još uvijek, gotovo trideset godina poslije raspada Jugoslavije, ideološki ocrnjuje povijest i dijeli što je nedjeljivo te, što je možda najgore, šuti ispred kvalitete arhitekture i promovira njezino uništavanje. Narativ, kojega sigurno povjesničari i aktivisti neće promijeniti, ali će ipak, prije ili poslije, to napraviti povijest. 
